\title{
Lactational Exposure to Polychlorinated Biphenyls, Dichlorodiphenyltrichloroethane, and Dichlorodiphenyldichloroethylene and Infant Growth: An Analysis of the Pregnancy, Infection, and Nutrition Babies Study
}

\author{
I-Jen Pan ${ }^{1}$, Julie L. Daniels ${ }^{1,2}$, Amy H. Herring ${ }^{3,4}$, Walter J. Rogan ${ }^{5}$, Anna Maria Siega- \\ Riz $^{1,4,6}$, Barbara D. Goldman ${ }^{7}$, and Andreas Sjödin ${ }^{8}$ \\ ${ }^{1}$ Department of Epidemiology, University of North Carolina, Chapel Hill, NC 27599, USA \\ ${ }^{2}$ Department of Maternal and Child Health, University of North Carolina, Chapel Hill, NC 27599, \\ USA \\ ${ }^{3}$ Department of Biostatistics, University of North Carolina, Chapel Hill, NC 27599, USA \\ ${ }^{4}$ Carolina Population Center, University of North Carolina, Chapel Hill, NC 27599, USA \\ ${ }^{5}$ Epidemiology Branch, National Institute of Environmental Health Sciences, National Institutes of \\ Health, Research Triangle Park, NC 27709, USA \\ ${ }^{6}$ Department of Nutrition, University of North Carolina, Chapel Hill, NC 27599, USA \\ ${ }^{7}$ Frank Porter Graham Child Development Institute, University of North Carolina at Chapel Hill, \\ Chapel Hill, NC 27599, USA \\ ${ }^{8}$ Organic Analytical Toxicology Branch, Division of Laboratory Sciences, National Center for \\ Environmental Health, Centers for Disease Control and Prevention, Atlanta, GA 30333, USA
}

\section{Summary}

Polychlorinated biphenyls (PCBs), 2,2-bis( $p$-chlorophenyl)-1,1,1-trichloroethane ( $p, p^{\prime}$-DDT) and 2,2-bis( $p$-chlorophenyl)-1,1-dichloroethylene ( $p, p^{\prime}$-DDE), the most stable metabolite of $p, p$ '-DDT, are persistent organic pollutants and environmental endocrine disruptors. Infant exposure to these chemicals through breast feeding may influence children's growth, but this potential adverse effect could be complicated by the co-existing benefits of breast feeding. This study examined the associations between lactational exposure to these chemicals and infant growth in the first 12 months by using data from the Pregnancy, Infection and Nutrition Babies Study in central North Carolina, United States, 2004-2006. The study population was restricted to the infants who were breastfed for 6 months or longer. PCBs, $p, p^{\prime}$-DDT and $p, p^{\prime}$-DDE were measured in breast milk at 3 months postpartum. Lactational exposure through 12 months was estimated as the product of chemical concentrations and the duration of breast feeding. The infant's weight and length were recorded from the medical record for each routine pediatric well-child visit in the first 12 months. Women-child pairs who breastfed for 6 months or longer and returned the growth card $(n=210)$, were included in the study. Linear mixed effects models were used to assess the associations between chemical concentrations in breast milk and longitudinal infant weight and length measurements in the first 6 months. Multivariable linear regression models were used to assess the relationships between lactational exposure to chemicals through 12 months and the z-scores of infant weight, length and weight-for-length at 12 months. Overall, no association was observed.

Corresponding Author: Julie L. Daniels, Ph.D., Department of Epidemiology, CB\#7435, University of North Carolina, Chapel Hill, NC, 27599-7435, Phone: +1-919-966-7096, Fax: +1-919-966-2089, julie_daniels@unc.edu. 
Breast feeding for 6 months or longer, with lactational exposure to PCBs, $p, p^{\prime}$-DDT and $p, p^{\prime}$-DDE at the low background level concentrations studied here, results in no measurable influence on infant growth in the first 12 months.

\section{INTRODUCTION}

The first 12 months of life is a period of dramatic change in babies' physical growth. Infants gain weight at a rate of about $680 \mathrm{~g}$ per month during the first 5 to 6 months 1 . By the end of the first year, weight triples, and body length increases by approximately $50 \% 1$. Growth in infancy has been related to long-term outcomes such as children's cognition, pubertal development, adult obesity, chronic diseases, and workplace success $2^{-}$. Infant growth retardation can be due to intrauterine growth inhibition, early childhood diseases, malnutrition, or disruption of hormone systems, potentially caused by environmental pollutants.

Polychlorinated biphenyls (PCBs), 2,2-bis( $p$-chlorophenyl)-1,1,1-trichloroethane ( $p, p^{\prime}$ DDT) and its most stable metabolite, 2,2-bis( $p$-chlorophenyl)-1,1-dichloroethylene ( $p, p$ 'DDE), are persistent organic compounds in the environment, which have been recognized as endocrine disruptors 10. In vivo and in vitro studies have shown that PCBs may alter dopamine, estrogen and thyroid effects $11^{-} 14 . p, p^{\prime}$-DDT has been suspected to have estrogenic effects, and $p, p^{\prime}$-DDE is known as an antiandrogen $15^{-} 19$. The potential for these compounds to interfere with the endocrine system could adversely affect infant development and growth.

The main route of exposure to PCBs, $p, p^{\prime}$-DDT and $p, p^{\prime}$-DDE for infants is through breast feeding. As the duration of lactation increases, the infant's accumulated dose of these long half-life chemicals increases. Exclusive breast feeding up to 6 months postpartum is recommended by the World Health Organization (WHO) because breast milk provides essential nutrients that an infant needs for growth and development 20. Assessing the adverse effects of chemical exposure through breast feeding is thus complicated by the coexisting beneficial attributes. In addition, breast-fed infants compared to formula-fed infants generally gain less weight in the first twelve months without much difference in length 21 , 22. Breast feeding per se could affect infant growth.

This study estimated the relationships between lactational exposure to PCBs, $p, p$ '-DDT and $p, p$ '-DDE and infant growth in the first 12 months using two methods. First, the study population was restricted to the infants who were breastfed for 6 months or longer to make breast feeding duration in the first 6 months uniform across the sample. This allowed us to assess the effects of chemical exposure on growth in the first 6 months independently from effects of breast feeding duration. Second, the effects of exposure to the accumulated chemicals over the first 12 months of life were examined, incorporating duration of breast feeding into an exposure metric.

\section{MATERIALS AND METHODS}

\section{Study population}

The Pregnancy, Infection and Nutrition (PIN) Babies Study followed the infants of the PIN and PIN Postpartum Study participants from January 2004 to the end of 2006. These studies enrolled pregnant women receiving prenatal care at the University of North Carolina Hospitals before 20 weeks gestation and followed them through the first year postpartum. Mothers completed several self-administered questionnaires and two phone interviews during pregnancy, one brief questionnaire after delivery in the hospital, and two in-home 
interviews at 3 and 12 months postpartum to provide details about their health and lifestyle during and after pregnancy. Infants in the PIN Babies studies were singletons without major birth defects. Details of these studies are available at the website:

http://www.cpc.unc.edu/projects/pin/. The protocols of all the PIN studies have been approved by the Institutional Review Board of the University of North Carolina at Chapel Hill, and written informed consent was obtained from all participating mothers.

Three hundred and four of the participant women in the PIN Babies Study ( $\mathrm{n}=585)$ were still lactating at 3 months postpartum and willing to provide a valid breast milk sample. They followed the written instructions to pump both breasts at around 10 o'clock in the morning of the scheduled interview. They gently mixed the milk extracted, used the plastic pipette to transfer the milk into three $1.5 \mathrm{ml}$ tubes, and stored the milk in the freezer until the interviewers arrived. Samples were then transported on ice to the $-80^{\circ} \mathrm{C}$ storage freezers.

Two hundred and sixty-four of the 304 women continued participation in the postpartum 12month in-home interview. Infant feeding methods for each preceding month was reported at these two home interviews 3 and 12 months postpartum (as further described below). Two hundred and fifty-three women were thus identified as breast feeding for 6 months or longer in the first year.

\section{Growth measurement}

Mothers were provided with an infant growth card to take to their child's 12-month pediatric well-child visit. The children's medical care providers completed the growth card by abstracting the infant's weight and length at each routine clinical visit from birth through 12 months from the medical record. The schedule for visits recommended by the American Academy of Pediatrics is at 1, 2, 4, 6, 9, and 12 months of age, but actual dates of visits were recorded because the frequency and times of visits varied among infants. The growth card was then collected at the 12-month home visit.

The weights and lengths of infants were compared to nationally representative data, the 2000 Centers for Disease Control and Prevention (CDC) growth charts, to determine their age-and gender-standardized z-scores of weight, length and weight-for-length 23 . Growth measurements were considered as biologically implausible if the z-scores were in the fixed exclusion range suggested by the World Health Organization 24. The 2000 CDC growth charts were based on a mix of both breast-fed and formula-fed infants, in which only $33 \%$ of infants were breast-fed for 3 months or longer. In general, the weights of the infants in this study were likely to be on the "light" side on the 2000 charts because the entire sample breastfed for 6 months or longer.

\section{Exposure measurement}

Breast milk samples were analyzed for $p, p^{\prime}$-DDT, $p, p^{\prime}$-DDE and thirty-five PCB congeners according to the existing methodology at the Organic Analytic Toxicology Branch of the National Center for Environmental Health at the CDC 25. The measurement of selected chemicals in breast milk samples was performed using gas chromatography/isotope dilution high-resolution mass spectrometry (GC/IDHRMS) using a MAT95 instrument (ThermoFinnigan MAT; Bremen, Germany). The lipid concentration was gravimetrically determined by an analytical balance AX105 Delta Range (Mettler Toledo; Columbus, $\mathrm{OH}$ ) with an accuracy of $\pm 10^{-4} \mathrm{~g}$. Each analysis batch contained sixteen unknowns, two method blanks and two quality control specimens. The between-assay coefficient of variation was normally less than $10 \%$. Concentrations reported here were all lipid adjusted. PCB 153 and $p, p^{\prime}$-DDE were detected in all 304 samples, and $p, p^{\prime}$-DDT was detected in 292 samples (96\%). Total PCBs was calculated as the sum of the eighteen PCB congeners that were 
detectable in more than $70 \%$ of samples, that is PCBs $66,74,99,105,118,138$ 158, 146, $153,156,170,177,178,180,183,187,194,196 \_203$ and 199. Concentrations lower than the limits of detection (LOD) were imputed to the median of the method LOD of each measurement divided by the square root of 226 .

\section{Lactational exposure metric}

In addition to using the lipid-adjusted chemical concentrations measured in breast milk at three months postpartum as an infant's exposure measurement, a Lactational Exposure Metric (LEM), a function of the lipid-adjusted chemical concentration in breast milk and the durations of breast feeding, was developed to represent an infant's cumulative exposure to each chemical at 12 months.

Durations of breast feeding were estimated from the two home interviews at 3 and 12 months postpartum. At these two interviews, women were asked to recall their feeding practices for each of the preceding months, indicating the frequency that they breastfed, fed infant formula, and fed other types of food. For each month, feeding status was classified. Exclusively breast feeding was defined as breast feeding with no other food or liquid; mostly breast feeding was defined as breast feeding with feeding of other supplements $\leq 1$ time per day; and breast feeding with supplements was defined as breast feeding with feeding any other liquids or solids $>1$ time per day. The number of months representing each type of feeding was summed and used in LEM.

The LEM was developed as follows:

$$
\mathrm{LEM}=\mathrm{C} \times\left(\mathrm{D}_{1}+\mathrm{D}_{2}\right)+\frac{1}{2} \times \mathrm{C} \times \mathrm{D}_{3},
$$

in which $\mathrm{C}$ denotes lipid-adjusted chemical concentration in breast milk (ng/g lipid), $\mathrm{D}_{1}$ is duration of exclusively breast feeding (months), $\mathrm{D}_{2}$ is duration of mostly breast feeding (months), and $\mathrm{D}_{3}$ is duration of breast feeding with supplements (months). The unit of this estimate is concentration-months, i.e. (ng/g)-months. Using this metric, breast milk concentration for each chemical was assumed to be constant through the lactation period, and breast milk consumption was assumed to be decreased by half during the period of breast feeding with supplements.

\section{Statistical analysis}

To estimate the relationships between lactational exposure to PCBs, $p, p^{\prime}$-DDT and $p, p^{\prime}$ DDE and infant growth, two statistical analyses were conducted using PC-SAS (version 9.1). In the first analysis, linear mixed effects models (PROC MIXED) were used to assess the relations between PCB153, total PCBs, $p, p^{\prime}$-DDT and $p, p$ '-DDE concentration in breast milk and longitudinal infant weight (grams) and length (centimeters) measurements in the first 6 months 27. The concentrations of PCB153, total PCBs, $p, p^{\prime}$-DDT and $p, p^{\prime}$-DDE in breast milk at 3 months postpartum were included in the separate mixed models as timeindependent variables. Infant age at the pediatric well-child visits was a time dependent variable, and centered at 90 days. A linear term, a quadratic term and a cubic term of infant age at the visit were included in the model to allow a curvilinear growth pattern. Models also included a random intercept and a random slope for infant age to allow infants to have their own growth patterns. The interaction terms between infant age and gender, between infant age and preterm status, between infant age and maternal race, and between infant gender and the concentrations of chemicals were added in the models and assessed by likelihood ratio tests using maximum likelihood. The a priori $\alpha$-level for interaction tests was 0.1 . The rationale for including the interaction terms between infant age and gender, between infant 
age and preterm status, and between infant age and maternal race was to allow the infant growth curves vary by gender, preterm status and race. The rationale for including the interaction term between infant gender and the chemical concentration was to examine whether the chemical's effect estimate was modified by gender, which was once reported in the literature. Influence statistics were assessed to examine how observations impacted the effect estimators 28 . The parameters in the final models were estimated using restricted maximum likelihood. Other covariates, which were included in the final model as timeindependent variables, were potential confounders and the important determinants of the outcomes: infant gender (male vs. female), preterm birth (yes vs. no), birthweight (grams), maternal race (nonwhite vs. white), education ( $<16$ years vs. $\geq 16$ years), income as a percentage of the poverty level during pregnancy (100\%), parity ( 0 vs. $\geq 1)$, and maternal pre-pregnancy body mass index $\left(\mathrm{kg} / \mathrm{m}^{2}\right)$.

In the second analysis, multivariable linear regression models were used to assess the relationships between lactational exposure to PCB153, total PCBs, $p, p$ '-DDT and $p, p$ '-DDE through 12 months, which was estimated by LEM, and the z-scores of infant weight, length and weight-for-length at 12 months. Infants who had a growth measurement in the interval $12 \pm 1.5$ months were included in this analysis. If there were multiple measurements within this range, we used the one measured at the age closest to 12 months. To control the confounding effects from breast feeding, we first modeled the associations between the duration of breast feeding and z-scores of weight, z-scores of length and z-scores of weightfor-length separately using simple linear regression. The residuals of the simple linear regression models were then included in the multiple linear regression models as dependent variables to estimate the effects of the LEM. Other covariates included in the linear regression models were z-score of birthweight, preterm birth (yes vs. no), maternal race (nonwhite vs. white), education ( $<16$ years vs. $\geq 16$ years), income as a percentage of the poverty level during pregnancy (100\%), parity ( $0 \mathrm{vs.} \geq 1)$ and maternal pre-pregnancy body mass index $\left(\mathrm{kg} / \mathrm{m}^{2}\right)$. Gender and LEM interaction was included in the models and assessed by the likelihood ratio test (a priori $\alpha$-level $=0.10$ ). Robust regression with Least Trimmed Squares (LTS) estimation for multiple linear regression models was used to examine the influence on beta coefficients by the outliers of chemical concentrations 29 .

\section{RESULTS}

Among 253 women who breastfed for 6 months or longer, 210 women returned the growth card. The study population was primarily white women with 16 or more years of education who were about 31 years of age at the start of pregnancy (Table 1). Comparison of the 210 mother-child pairs in the growth card subgroup with the original 304 participants showed that those who breastfed for 6 months or longer and also participated in the follow-up studies were more highly educated and more likely to be white women. However, this subgroup had similar distributions of chemical concentrations and LEMs to those of the original population. In the subgroup of 210 mother-child pairs, one infant had no records of clinical visits in the first 6 months and was not included in the mixed models; 9 infants had no clinical visits around 12 months and were not included in the linear regression models.

Children averaged 3.7 (range 1 to 7) well-child visits in the first 6 months. A total of 774 visits for 209 infants were included in the analysis; 537 of these 774 visits occurred before the age of 3 months. After controlling for other covariates in the mixed models, the growth curves of infant weight and length through 6 months were not related to the concentrations of PCB153, total PCBs, $p, p^{\prime}-\mathrm{DDT}$ and $p, p^{\prime}$-DDE (Table 2). Excluding the chemical concentration outliers, i.e. $>$ mean +3 standard deviations (SD), ( 2 infants for analysis of PCB153, 3 for total PCBs, and 4 for $p, p^{\prime}-\mathrm{DDT}$ and $p, p^{\prime}$-DDE) only changed the magnitudes of effect estimates ( $\beta \mathrm{s}$ ) by 11.1 (for PCB153), 5.2 (for total PCBs), 46.4 (for DDT) and 2.7 
(for DDE) in the mixed models for body weight (grams) and changed the magnitudes of effect estimates $(\beta \mathrm{s})$ by 0.01 or less in the mixed models for body length (centimeters). All the confidence intervals $(\mathrm{CI})$ of the associations became wider and still remained inclusive of zero (data not shown). Quadratic and cubic terms of the chemical concentration were considered to examine the possibility of curvilinear associations; but because they were not statistically significant and complicated the interpretation, they were excluded in the final models.

The interaction terms between infant age and gender, infant age and preterm status, and infant age and maternal race contributed to the fit of the models, which indicated the growth curves of weight in the first 6 months varied by gender, preterm status and maternal race; however, in the models of length, the growth curves did not vary by maternal race. The likelihood ratio tests for the interaction between the chemical concentrations and gender had p-values greater than 0.1 , so the effects of chemicals were not modified by infant gender.

At twelve months, the mean weight of 201 infants who had medical visits at 12 months was 9,581 grams $(\mathrm{SD}=1,128)$ and the mean $\mathrm{z}$-score of weight was $-0.50(\mathrm{SD}=1.03)$. The mean length was 75.7 centimeters $(\mathrm{SD}=2.7)$ and the mean $\mathrm{z}$-score of length was $0.17(\mathrm{SD}=$ $0.88)$. The mean $z$-score of weight-for-length was $-0.26(\mathrm{SD}=1.16)$. As the duration of breast feeding increased by a month, the z-scores of weight, length and weight-for-lengths at 12 months decreased by $0.12(P<0.001), 0.06(P=0.06)$ and $0.10(P<0.01)$ respectively. Table 3 shows that after covariate adjustment, no differences in z-scores of weight, length, or weight-for-length were observed with increases in LEM of PCB153, PCBs, $p, p$ '-DDT and $p, p$ '-DDE. Gender did not modify measurements of the LEM effect, except for the interaction term between $p, p^{\prime}$-DDT and gender in the model of infant weight $(P=0.07)$. However, the effect estimates of $p, p$ '-DDT stratified by infant gender were still inclusive of 0 (male: $\beta=-0.0229$ [95\%CI $=-0.0602,0.0144]$; female: $\beta=0.0122$ [95\% CI $=-0.0218$, $0.0462])$. Robust regression identified 1 to 3 outliers $(0.5$ to $1.5 \%)$ in the multivariable linear regression models, but results remained unchanged. Quadratic and cubic terms of the LEM were considered to examine the possibility of curvilinear associations; but because they were not statistically significant and complicated the interpretation, they were excluded in the final models.

\section{DISCUSSION}

Our results suggest that among infants breastfed for 6 months or longer, there was no difference in weight and length through the first 6 months as the concentration of PCBs, $p, p$ '-DDT and $p, p$ '-DDE in breast milk increased. No difference was observed in weight, length and weight-for-length at 12 months when comparing the accumulated lactational exposure through 12 months after controlling for total duration of breast feeding. No sexspecific association was observed.

The associations between PCBs, $p, p^{\prime}$-DDT and $p, p$ '-DDE and children's growth have not been consistent throughout the literature, nor has the effect modification of gender. Inconsistent results may be due to different exposure periods assessed (prenatal, lactational or childhood), different chemical concentration distributions in the study populations, different mixtures of environmental chemicals across studies, or inadequate confounding control for duration of breast feeding. This study measured chemical concentrations in breast milk at 3 months postpartum to examine the effects of infants' lactational exposure. The study population was exposed to low background levels reflected by the relatively lower chemical concentrations compared to other previous studies. Because breast feeding itself can affect growth patterns, we restricted the analyses to those breastfed for 6 months or 
longer. This restriction should have minimized the potential for confounding by the duration of breast feeding.

Despite different methods of exposure estimation and different time windows of outcome measurements, this study supported previous findings of no association between children's growth and postnatal exposure to PCBs $30^{-} 32$. Our results contrast those from the Faroe Islands cohort study, which suggested an increase in lactational exposure, estimated by the product terms of chemical concentrations and the duration of exclusive breast feeding, decreased body height and weight at 18 months 33 . PCB 153 concentrations in breast milk from the women in Faroe Islands were on the order of more than 20 times greater than those in our study 34 . As for prenatal exposure to PCBs in previous studies, children with higher prenatal PCBs were reported to be shorter from birth to 3 months of age in a formula-fed group in the Dutch cohort 31, but higher prenatal PCBs were associated with greater height among 5-year-old girls in the California study 35. A negative association with body weight was observed only among girls in the small subset of the Collaborative Perinatal Project (CPP) cohort in New York 36 and in a Michigan cohort of polybrominated biphenyl accident victims 37 . This negative association was found without gender differentiation among 4-year-old children in the Michigan fish consumption cohort 30, and from birth to 3 months in a formula-fed group in the Dutch cohort 31. However, two other studies reported that no difference was observed in children's growth when prenatal exposure to PCBs increased $38,39$.

No prior studies have investigated lactational exposure to $p, p$ '-DDT and $p, p^{\prime}$-DDE in relation to infant growth. In several studies of prenatal exposure to $p, p$ '-DDT and $p, p$ '-DDE, no difference was observed in children's growth $36,39,40$. However, the CPP cohort found a negative association between prenatal $p, p^{\prime}$-DDE and children's height at 1, 4 , and 7 years 38. This negative association was also found only among girls in the German study using the concentrations detected in children's blood at 8 years of age to index perinatal exposure 32 . There were about $5 \%$ of women smoking postpartum in the PIN Babies Study, so this study had limited statistical power to examine the interaction between DDE and maternal smoking on children's growth suggested by the Belgian study 41 .

In this study, the concentration of PCB153, the most prevalent congener, was highly correlated with the concentrations of mono-ortho-chlorinated PCBs, di-ortho-chlorinated PCBs, and tri-ortho-chlorinated PCBs; the Pearson correlation coefficients were 0.76, 0.99, and 0.80 respectively. Thus, it is unlikely that using ortho-substituted groupings of PCB congeners would provide different results from using PCB153 only. Indeed, no associations were found when analyzing data using ortho-substituted groupings of PCB congeners. In addition, providing the effect estimates of single PCB153 concentration would facilitate the comparisons across studies. Plíšková et al. reported that PCBs 138, 153, 170, 180, 187, 194, 199 and 203 in ER-CALUX assay showed antiestrogenic effects 42. By grouping PCB congeners based on suggested antiestrogenicity, the magnitude of the association between PCBs and infant weight in the first 6 months became smaller than with PCB153 only ( $\beta$ in the mixed model $=-8.4[-16.6,-0.25])$ and the estimate was at the borderline of significance $(P=0.04)$. No other associations were found.

The lactational exposure metrics used in this study can reflect an infant's accumulated lactational exposure through the first 12 months. According to the Hooper et al study 43, the PCB 153 concentration in breast milk decreased $4 \%$ over the first 6 months of breast feeding; after 6 months, the PCB153 concentration did not change more than 1\% per month. Among 83 women in our study who had concentrations available in both 3-month and 12-month breast milk samples, there was no statistical difference in the concentrations of PCB153, PCBs, $p, p^{\prime}$-DDT and $p, p^{\prime}$-DDE. These findings support the assumption of a relatively 
constant concentration throughout the lactation period. Additionally, under the two assumptions that infants in the same feeding status group consumed similar amounts of breast milk and that the mothers had similar fat composition in their breast milk, the LEM should be highly correlated with the absolute value of the accumulated dose of the chemicals. Although the LEM is appropriate for estimating the relative effects of chemical exposure, results using this method may still be affected by the potential for non-differential exposure misclassification based on our assumptions and recall errors. Such bias would tend to shift effect estimates toward the null.

For the investigation on the growth trajectory in the first 6 months, the concentration of chemicals in breast milk was used in the mixed models. This measurement should be highly correlated with the accumulated exposure through the first 6 months because all the infants in this study were breastfed for at least 6 months and $90 \%$ of the infants were exclusively or mostly breastfed for 4 months or longer. This selection criterion provided comparability among the infants, and also provided an unambiguous measure of the chemical effect independent of the duration of breast feeding. We also used the LEM at each pediatric wellchild visit as a time-dependent variable in the mixed models, and the findings confirmed the results of no association.

The logarithmic transformation of the concentrations of PCB153, total PCBs, $p, p$ '-DDT and $p, p$ '-DDE was considered for the general linear mixed models, but it did not substantially improve the normality of residuals or reduce leverage points. We decided to use a linear term of the concentrations in the models for simplicity and ease of interpretation.

Several limitations of this study should be noted. This study population was primarily welleducated white mothers, which may constrain the generalization of the findings, especially if the heterogeneous effects of race and socioeconomic status were believed to be true. There were no direct measurements of prenatal exposure to PCBs, $p, p^{\prime}$-DDT and $p, p^{\prime}$-DDE in this study, thus the effects of lactational exposure could not be differentiated from the effects of prenatal exposure. However, we adjusted for infant birthweight in the mixed models and adjusted the z-scores of birthweight in the multiple linear regression models to control for the potential adverse effects of prenatal exposure on intrauterine growth.

Women have been encouraged to breastfeed for at least 6 months by the WHO and the American Academy of Pediatrics. Although longer durations of breast feeding may involve increased exposure to potentially hazardous chemicals, our study indicates that breast feeding for 6 months or longer, with lactational exposure to PCBs, $p, p^{\prime}$-DDT and $p, p^{\prime}$-DDE in the ranges of low background level concentrations studied here, results in no measurable influence on infant growth in the first 12 months.

\section{Acknowledgments}

This work was supported by the National Institute of Environmental Health Sciences [grant number P30ES10126]; and the U.S. Environmental Protection Agency [grant number RD832736]. Dr. Rogan's work on this project was supported by the Intramural Research Program, National Institute of Environmental Health Sciences, National Institutes of Health. Authors declare they have no conflict of interest.

\section{REFERENCES}

1. Chamley, CA. Developmental anatomy and physiology of children : a practical approach. 1st ed.. Edinburgh, UK: Elsevier/Churchill Livingstone; 2005.

2. Mendez MA, Adair LS. Severity and timing of stunting in the first two years of life affect performance on cognitive tests in late childhood. The Journal of Nutrition. 1999; 129:1555-1562. [PubMed: 10419990] 
3. Dunger DB, Ahmed ML, Ong KK. Early and late weight gain and the timing of puberty. Molecular and Cellular Endocrinology. 2006; 254-255:140-145.

4. Baird J, Fisher D, Lucas P, Kleijnen J, Roberts H, Law C. Being big or growing fast: systematic review of size and growth in infancy and later obesity. British Medical Journal. 2005; 331:929-931. [PubMed: 16227306]

5. Monteiro PO, Victora CG. Rapid growth in infancy and childhood and obesity in later life--a systematic review. Obesity Reviews. 2005; 6:143-154. [PubMed: 15836465]

6. Barker DJ. The developmental origins of chronic adult disease. Acta Paediatrica Supplement. 2004; 93:26-33. [PubMed: 15702667]

7. Rolland-Cachera MF. Rate of growth in early life: a predictor of later health? Advances in Experimental Medicine and Biology. 2005; 569:35-39. [PubMed: 16137104]

8. La Batide-Alanore A, Tregouet DA, Sass C, Siest G, Visvikis S, Tiret L. Family study of the relationship between height and cardiovascular risk factors in the STANISLAS cohort. International Journal of Epidemiology. 2003; 32:607-614. [PubMed: 12913037]

9. Judge TA, Cable DM. The effect of physical height on workplace success and income: preliminary test of a theoretical model. Journal of Applied Psychology. 2004; 89:428-441. [PubMed: 15161403]

10. Longnecker MP, Rogan WJ, Lucier G. The human health effects of DDT (dichlorodiphenyltrichloroethane) and PCBs (polychlorinated biphenyls) and an overview of organochlorines in public health. Annual Review of Public Health. 1997; 18:211-244.

11. Seegal RF. Epidemiological and laboratory evidence of PCB-induced neurotoxicity. Critical Reviews in Toxicology. 1996; 26:709-737. [PubMed: 8958469]

12. Hauser P, McMillin JM, Bhatara VS. Resistance to thyroid hormone: implications for neurodevelopmental research on the effects of thyroid hormone disruptors. Toxicology and Industrial Health. 1998; 14:85-101. [PubMed: 9460171]

13. Hagmar L. Polychlorinated biphenyls and thyroid status in humans: a review. Thyroid. 2003; 13:1021-1028. [PubMed: 14651786]

14. Faroon OM, Keith S, Jones D, de Rosa C. Effects of polychlorinated biphenyls on development and reproduction. Toxicology and Industrial Health. 2001; 17:63-93. [PubMed: 12117298]

15. Kelce WR, Stone CR, Laws SC, Gray LE, Kemppainen JA, Wilson EM. Persistent DDT metabolite p,p'-DDE is a potent androgen receptor antagonist. Nature. 1995; 375:581-585. [PubMed: 7791873]

16. Klotz DM, Ladlie BL, Vonier PM, McLachlan JA, Arnold SF. o,p'-DDT and its metabolites inhibit progesterone-dependent responses in yeast and human cells. Molecular and Cellular Endocrinology. 1997; 129:63-71. [PubMed: 9175630]

17. Sonnenschein C, Soto AM. An updated review of environmental estrogen and androgen mimics and antagonists. The Journal of Steroid Biochemistry and Molecular Biology. 1998; 65:143-150. [PubMed: 9699867]

18. Andersen HR, Andersson AM, Arnold SF, Autrup H, Barfoed M, Beresford NA, et al. Comparison of short-term estrogenicity tests for identification of hormone-disrupting chemicals. Environmental Health Perspectives. 1999; 107:89-108. [PubMed: 10229711]

19. Freyberger A, Ahr HJ. Development and standardization of a simple binding assay for the detection of compounds with affinity for the androgen receptor. Toxicology. 2004; 195:113-126. [PubMed: 14751668]

20. WHO. Global strategy for infant and young child feeding. Geneva, Switzerland: World Health Organization; 2003. UNICEF.

21. Dewey KG, Heinig MJ, Nommsen LA, Peerson JM, Lonnerdal B. Growth of breast-fed and formula-fed infants from 0 to 18 months: the DARLING Study. Pediatrics. 1992; 89:1035-1041. [PubMed: 1594343]

22. Hediger ML, Overpeck MD, Ruan WJ, Troendle JF. Early infant feeding and growth status of USborn infants and children aged 4-71 mo: analyses from the third National Health and Nutrition Examination Survey, 1988-1994. American Journal of Clinical Nutrition. 2000; 72:159-167. [PubMed: 10871575] 
23. Kuczmarski RJ, Ogden CL, Guo SS, Grummer-Strawn LM, Flegal KM, Mei Z, et al. CDC Growth Charts for the United States: methods and development. Vital and Health Statistics, Series 11, Number 246. 2002:1-190.

24. Cut-offs to define outliers in the 2000 CDC Growth Charts. Washington, DC: Department of Health and Human Services, Centers for Disease Control and Prevention; 2005 [updated 2005; cited 2008 June 1]. Available from: http://www.cdc.gov/nccdphp/dnpa/growthcharts/resources/BIV-cutoffs.pdf

25. Sjodin A, McGahee EE 3rd, Focant JF, Jones RS, Lapeza CR, Zhang Y, et al. Semiautomated high-throughput extraction and cleanup method for the measurement of polybrominated diphenyl ethers and polybrominated and polychlorinated biphenyls in breast milk. Analytical Chemistry. 2004; 76:4508-4514. [PubMed: 15283595]

26. Hornung RW, Reed LD. Estimation of average concentration in the presence of nondetectable values. Applied Occupational and Environmental Hygiene. 1990; 5:46-51.

27. Cnaan A, Laird NM, Slasor P. Using the general linear mixed model to analyse unbalanced repeated measures and longitudinal data. Statistics in Medicine. 1997; 16:2349-2380. [PubMed: 9351170]

28. Schabenberger, O. Mixed model influence diagnostics; Cary, NC. Twenty-Ninth Annual SAS Users Group International Conference (SUGI29); SAS Institute Inc; 2004. p. 1-17.

29. Chen C. Robust Regression and Outlier Detection with the ROBUSTREG Procedure. SAS Users Group International Conference (SUGI). 2002; 265-27:1-12.

30. Jacobson JL, Jacobson SW, Pagano J. Effects of exposure to PCBs and related compounds on growth and activity in children. Neurotoxicology and Teratology. 1990; 12:319-326. [PubMed: 2118230]

31. Patandin S, Koopman-Esseboom C, de Ridder MA, Weisglas-Kuperus N, Sauer PJ. Effects of environmental exposure to polychlorinated biphenyls and dioxins on birth size and growth in Dutch children. Pediatric Research. 1998; 44:538-545. [PubMed: 9773843]

32. Karmaus W, Asakevich S, Indurkhya A, Witten J, Kruse H. Childhood growth and exposure to dichlorodiphenyl dichloroethene and polychlorinated biphenyls. Journal of Pediatrics. 2002; 140:33-39. [PubMed: 11815761]

33. Grandjean P, Budtz-Jorgensen E, Steuerwald U, Heinzow B, Needham LL, Jorgensen PJ, et al. Attenuated growth of breast-fed children exposed to increased concentrations of methylmercury and polychlorinated biphenyls. The Journal of the Federation of American Societies for Experimental Biology. 2003; 17:699-701.

34. Fangstrom B, Strid A, Grandjean P, Weihe P, Bergman A. A retrospective study of PBDEs and PCBs in human milk from the Faroe Islands. Environmental Health: A Global Access Science Source. 2005; 4:12. [PubMed: 16014177]

35. Hertz-Picciotto I, Charles MJ, James RA, Keller JA, Willman E, Teplin S. In utero polychlorinated biphenyl exposures in relation to fetal and early childhood growth. Epidemiology. 2005; 16:648656. [PubMed: 16135941]

36. Lamb MR, Taylor S, Liu X, Wolff MS, Borrell L, Matte TD, et al. Prenatal exposure to polychlorinated biphenyls and postnatal growth: a structural analysis. Environmental Health Perspectives. 2006; 114:779-785. [PubMed: 16675437]

37. Blanck HM, Marcus M, Rubin C, Tolbert PE, Hertzberg VS, Henderson AK, et al. Growth in girls exposed in utero and postnatally to polybrominated biphenyls and polychlorinated biphenyls. Epidemiology. 2002; 13:205-210. [PubMed: 11880762]

38. Ribas-Fito N, Gladen BC, Brock JW, Klebanoff MA, Longnecker MP. Prenatal exposure to 1,1dichloro-2,2-bis (p-chlorophenyl)ethylene (p,p'-DDE) in relation to child growth. International Journal of Epidemiology. 2006; 35:853-858. [PubMed: 16606643]

39. Rogan WJ, Gladen BC, McKinney JD, Carreras N, Hardy P, Thullen J, et al. Polychlorinated biphenyls (PCBs) and dichlorodiphenyl dichloroethene (DDE) in human milk: effects on growth, morbidity, and duration of lactation. American Journal of Public Health. 1987; 77:1294-1297. [PubMed: 3115123] 
40. Jusko TA, Koepsell TD, Baker RJ, Greenfield TA, Willman EJ, Charles MJ, et al. Maternal DDT exposures in relation to fetal and 5-year growth. Epidemiology. 2006; 17:692-700. [PubMed: 17003683]

41. Verhulst SL, Nelen V, Hond ED, Koppen G, Beunckens C, Vael C, et al. Intrauterine exposure to environmental pollutants and body mass index during the first 3 years of life. Environmental Health Perspectives. 2009; 117:122-126. [PubMed: 19165398]

42. Pliskova M, Vondracek J, Canton RF, Nera J, Kocan A, Petrik J, et al. Impact of polychlorinated biphenyls contamination on estrogenic activity in human male serum. Environmental Health Perspectives. 2005; 113:1277-1284. [PubMed: 16203234]

43. Hooper K, She J, Sharp M, Chow J, Jewell N, Gephart R, et al. Depuration of polybrominated diphenyl ethers (PBDEs) and polychlorinated biphenyls (PCBs) in breast milk from California first-time mothers (primiparae). Environmental Health Perspectives. 2007; 115:1271-1275. [PubMed: 17805415] 
Table 1

Characteristics and Chemical Concentrations in Breast Milk of Participant Mothers Who Provided Breast Milk at 3 Months in the PIN Babies Study and also of the Mother-Child Pairs Included in this Paper, Central North Carolina, United States, 2004-2006.

\begin{tabular}{|c|c|c|c|c|}
\hline & \multicolumn{2}{|c|}{$\underset{(n=304)}{\text { Milk Samples }}$} & \multicolumn{2}{|c|}{$\begin{array}{c}\text { Growth Card Subgroup } \\
(\mathrm{n}=210)\end{array}$} \\
\hline & No. & $\%$ & No. & $\%$ \\
\hline \multicolumn{5}{|c|}{ Maternal characteristics } \\
\hline \multicolumn{5}{|l|}{ Race } \\
\hline White & 262 & 86 & 189 & 90 \\
\hline Non-white & 42 & 14 & 21 & 10 \\
\hline \multicolumn{5}{|c|}{ Education (years) } \\
\hline$<16$ & 54 & 18 & 28 & 13 \\
\hline$\geq 16$ & 250 & 82 & 182 & 87 \\
\hline \multicolumn{5}{|l|}{ Parity } \\
\hline 0 & 160 & 53 & 107 & 51 \\
\hline$\geq 1$ & 144 & 47 & 103 & 49 \\
\hline \multicolumn{5}{|l|}{ Age (years) } \\
\hline Mean (SD) & & $1(5)$ & & $31(5)$ \\
\hline \multicolumn{5}{|c|}{$\begin{array}{l}\text { Percent of } 2001 \text { poverty level } \\
\text { during pregnancy }(\%)\end{array}$} \\
\hline Mean (SD) & \multicolumn{2}{|c|}{490 (199) } & \multicolumn{2}{|c|}{$509(186$} \\
\hline Missing & \multicolumn{2}{|l|}{5} & \multicolumn{2}{|l|}{4} \\
\hline \multicolumn{5}{|c|}{$\begin{array}{l}\text { Pre-pregnancy body mass index } \\
\left(\mathrm{kg} / \mathrm{m}^{2}\right)\end{array}$} \\
\hline Mean (SD) & \multicolumn{2}{|c|}{$23.8(4.9)$} & \multicolumn{2}{|c|}{$23.5(4.8$} \\
\hline \multicolumn{5}{|c|}{$\begin{array}{l}\text { Median (range) of chemical } \\
\text { concentrations in breast milk } \\
\text { (ng/g lipid) }{ }^{a}\end{array}$} \\
\hline PCB153 & \multicolumn{2}{|c|}{$17(2-199)$} & \multicolumn{2}{|c|}{$18(2-199$} \\
\hline$\Sigma \mathrm{PCBs} b$ & \multicolumn{2}{|c|}{$77(9-708)$} & \multicolumn{2}{|c|}{$81(12-708$} \\
\hline$p, p^{\prime}-\mathrm{DDT}$ & \multicolumn{2}{|c|}{$5(<$ LOD -80$)$} & \multicolumn{2}{|c|}{$5(<\mathrm{LOD}-36$} \\
\hline$p, p^{\prime}-\mathrm{DDE}$ & \multicolumn{2}{|c|}{$121(1-2,140)$} & \multicolumn{2}{|c|}{$113(15-2,140$} \\
\hline \multicolumn{5}{|c|}{ Infant characteristics } \\
\hline \multicolumn{5}{|l|}{ Baby gender } \\
\hline Male & 163 & 54 & 113 & 54 \\
\hline Female & 141 & 46 & 97 & 46 \\
\hline \multicolumn{5}{|l|}{ Preterm birth } \\
\hline Yes & 22 & 7 & 16 & 8 \\
\hline No & 282 & 93 & 194 & 92 \\
\hline \multicolumn{5}{|c|}{ Birthweight (g) } \\
\hline Mean (SD) & \multicolumn{2}{|c|}{3406 (624) } & & (474) \\
\hline $\begin{array}{l}\text { Duration of b } \\
\text { (months) }\end{array}$ & & & & \\
\hline Mean (SD) & & $10(2)$ & & $11(2)$ \\
\hline
\end{tabular}




\begin{tabular}{|c|c|c|c|}
\hline & \multicolumn{2}{|c|}{$\underset{(\mathbf{n}=304)}{\operatorname{Milk} \text { Samples }}$} & $\begin{array}{c}\text { Growth Card Subgroup } \\
\qquad(\mathrm{n}=210)\end{array}$ \\
\hline & No. & $\%$ & No. \\
\hline Missing & 40 & & 0 \\
\hline \multicolumn{4}{|c|}{$\begin{array}{l}\text { Months of exclusive breast } \\
\text { feeding }\end{array}$} \\
\hline Mean (SD) & & $4(2)$ & $5(2)$ \\
\hline Missing & 40 & & 0 \\
\hline \multicolumn{4}{|c|}{$\begin{array}{l}\text { Median (range) of LEM at } 12 \\
\text { months (ng/g lipid - months) }\end{array}$} \\
\hline PCB153 & $119(1$ & ,194) & $126(19-1,194)$ \\
\hline$\Sigma \mathrm{PCBs} b$ & $546(6$ & , 249) & $574(100-4,249)$ \\
\hline$p, p^{\prime}-\mathrm{DDT}$ & & $-523)$ & $34(1-326)$ \\
\hline$p, p^{\prime}-\mathrm{DDE}$ & $871(134$ & ,260) & $880(134-19,260)$ \\
\hline
\end{tabular}

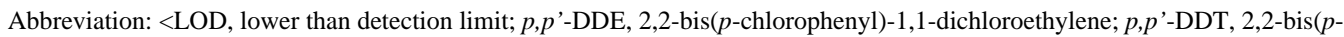
chlorophenyl)-1,1,1-trichloroethane; LEM, lactational exposure metrics; PCB, polychlorinated biphenyls; and SD, standard deviation.

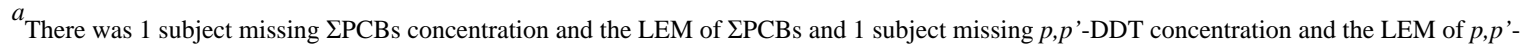
DDT. Additional 40 subjects in the milk sample group were missing LEM because of missing duration of breast feeding through 12 months.

$b_{\Sigma \mathrm{PCB}}$ is the sum of the concentrations of PCB66, PCB74, PCB99, PCB105, PCB118, PCB138_158, PCB146, PCB153, PCB156, PCB170, PCB177, PCB178, PCB180, PCB183, PCB187, PCB194, PCB196_203 and PCB199, in which <LOD is treated as median(LOD) divided by a square root of 2. 
Table 2

(Linear Mixed Effects Models) Fixed Effect Estimates of a $10 \mathrm{ng} / \mathrm{g}$-lipid Increase in the Concentrations of PCB153, PCBs, $p$, $p$ '-DDT and $p, p$ '-DDE in Breast Milk at 3 Months Postpartum on Infant Weight and Length in the First 6 Months.

\begin{tabular}{lrrrr}
\hline $\begin{array}{l}\text { Chemical concentration } \\
\text { (per 10 ng/g lipid) }\end{array}$ & \multicolumn{2}{c}{ Weight (g) } & \multicolumn{2}{c}{ Length (cm) } \\
& $\boldsymbol{\beta}^{\boldsymbol{a}}$ & $\mathbf{9 5 \%} \mathbf{C I}$ & $\boldsymbol{\beta} \boldsymbol{a}$ & $\mathbf{9 5 \%} \mathbf{C I}$ \\
\hline PCB153 & -23.1 & {$[-46.3,0.05]$} & -0.06 & {$[-0.20,0.09]$} \\
$\mathbf{\Sigma P C B s}$ & -6.2 & {$[-12.5,0.1]$} & -0.02 & {$[-0.06,0.02]$} \\
$\boldsymbol{p}, \boldsymbol{p}$ '-DDT & 17.6 & {$[-91.2,126.5]$} & 0.17 & {$[-0.47,0.82]$} \\
$\boldsymbol{p}, \boldsymbol{p}$ '-DDE & 0.5 & {$[-1.7,2.8]$} & 0.01 & {$[-0.005,0.02]$} \\
\hline
\end{tabular}

Abbreviation: CI, confidence interval; $p$,p'-DDE, 2,2-bis(p-chlorophenyl)-1,1-dichloroethylene; $p, p^{\prime}$-DDT, 2,2-bis(p-chlorophenyl)-1,1,1trichloroethane; and PCB, polychlorinated biphenyls.

\footnotetext{
${ }^{a}$ Adjusted for infant gender (male vs. female), preterm birth (yes vs. no), birthweight (grams), maternal race (nonwhite vs. white), education ( $<16$ years vs. $\geq 16$ years), income as a percentage of the poverty level during pregnancy $(100 \%)$, parity $(0$ vs. $\geq 1)$, and maternal pre-pregnancy body mass index $\left(\mathrm{kg} / \mathrm{m}^{2}\right)$. Interpretation of the $\beta$ was: in the first 6 months, infant weight or length would change by $\beta$ grams or centimeters as the chemical concentration in breast milk increased by $10 \mathrm{ng} / \mathrm{g}$ lipid after adjusted for all other covariates.
} 


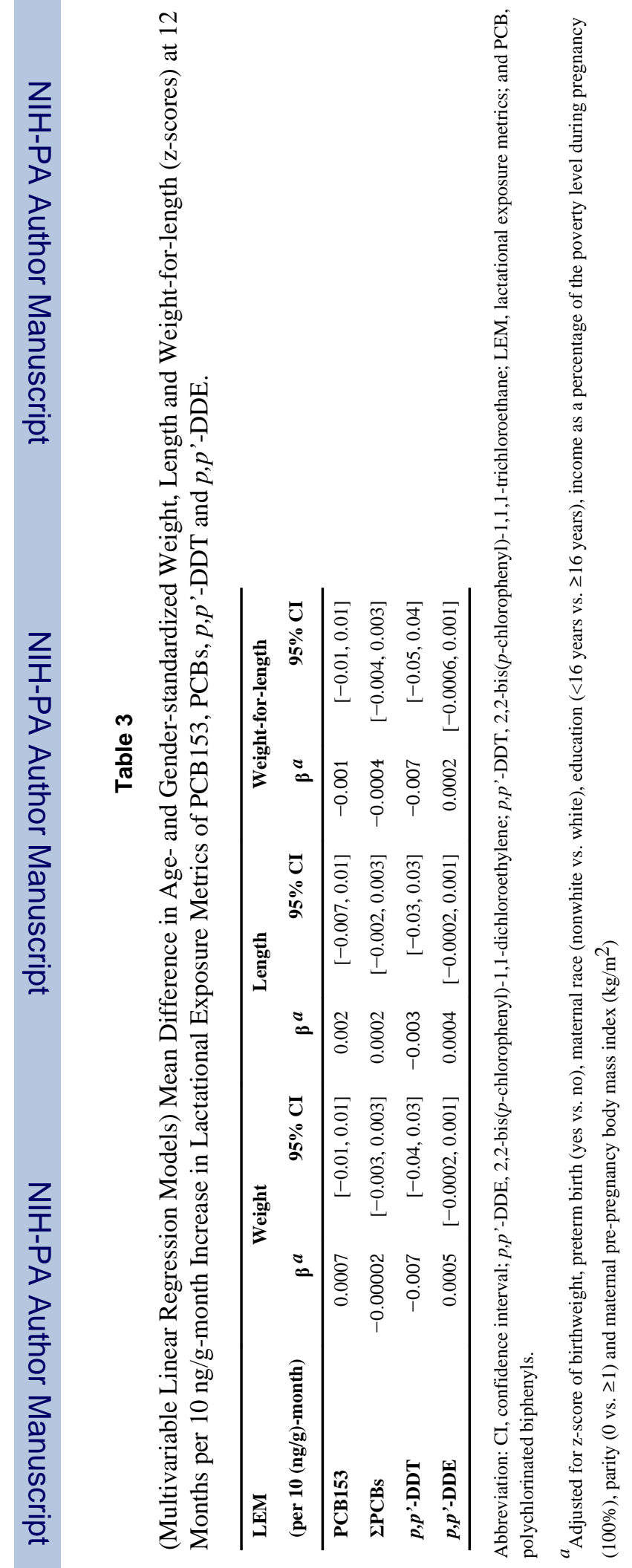

